\title{
Lengthy leader male tenure delays male offspring dispersal in a primate multilevel society
}

\author{
Gu Fang ${ }^{\text {a }}$, Xiao-Min Gao ${ }^{\text {a }}$, Dong Zhang ${ }^{\text {a }}$, Derek Dunn ${ }^{\text {a }}$, Ruliang Pan ${ }^{\text {a }}$, \\ Bao-Guo $\mathrm{Li}^{\mathrm{a}, \mathrm{b}}$ and Xiao-Guang Qi ${ }^{\mathrm{a}, *}$ \\ ${ }^{\text {a }}$ Shaanxi Key Laboratory for Animal Conservation, College of Life Sciences, Northwest \\ University, Xi' an 710069, P.R. China \\ ${ }^{\mathrm{b}}$ Center for Excellence in Animal Evolution and Genetics, Chinese Academy of Sciences, \\ Kunming 650223, P.R. China \\ *Corresponding author's e-mail address: qixg@nwu.edu.cn
}

Received 15 April 2019; initial decision 28 May 2019; revised 18 July 2019; accepted 24 July 2019; published online 3 September 2019

\begin{abstract}
Natal dispersals are male-biased in most Old World monkey species, especially those that are polygynous. We examined patterns of male dispersal in golden snub-nosed monkeys, in which male offspring mainly disperse as juveniles from their natal one-male units (OMUs) to a bachelor group. However, out of a total of 112 male dispersals from 2001-2016, we documented six cases in which male offspring remained in their natal OMU until sub-adulthood. Based on monitoring of dispersal dynamics, we found that male offspring were more likely to delay dispersal if the tenure of leader males was lengthy. Social network analysis showed male offspring who delayed dispersal exhibited strong social relationships with each other and their OMU leader male but not with the females of their OMU. Our results suggest that the length of leader male tenure may affect natal male dispersal due to benefits to leader males accrued via intrasexual competition and kin selection.
\end{abstract}

\section{Keywords}

natal male, male tenure, dispersal pattern, social network analysis (SNA), multilevel society.

\section{Introduction}

In many group-living species, males leave their natal group or transfer to other groups more commonly than females (DeVore, 1965; Van Noordwijk \& Van Schaik, 2004). In species that live in multi-male/multi-female social groups, males often disperse directly into a new group that contains more 
(estrous) females (e.g., olive baboons, Papio anubis: Packer, 1977; Steely et al., 2017, ursine colobus monkeys, Colobus vellerosus: Teichroeb et al., 2011), or into groups with a more favorable adult sex ratio (yellow baboon, P. cynocephalus: Alberts \& Altmann, 1995; Silk et al., 2009). In rhesus (Macaca mulatta) and Japanese macaques (M. fuscata), male-biased natal dispersals may enable individual males to gain a higher social rank, thus providing benefits via increased breeding opportunities (Drickamer \& Vessey, 1973; Huffman, 1991). In contrast, in species in which larger social groups are composed of several polygynous one-male/multi-female units (OMUs), male offspring usually leave their natal OMU before sexual maturity and either live alone or aggregate with other males into an all-male unit (AMB, or 'bachelor group') (Höner et al., 2007; e.g., white-headed langur, Trachypithecus leucocephalus: Wang \& Yao, 2017).

When mating opportunities are monopolized by a minority of dominant males, sexual selection (male-male competition and/or female choice) will result in reproduction being largely restricted to these males (Andersson, 1994; Pusey \& Packer, 2012). Among species comprised in polygynous OMUs, intra-sexual competition tends to occur between the leader males and younger sexually mature males that are yet to disperse (Mitani et al., 1996). Because these younger males are potential competitors for food, pose a threat of adult-male usurpation, and may mate surreptitiously with the adult females of their OMU (Arcese, 1989), leader males usually evict sub-adult males from their OMU (Perlman et al., 2016), especially if the leader male has just been replaced another male (Zhu et al., 2016).

However, young males benefit if they can prolong their stay within their natal group (Teichroeb \& Jack, 2017). For example, in crested macaques (Macaca nigra), young males attain their peak physical strength more quickly by staying in their natal group, which may allow them to obtain a larger body size before engaging in competition with fully adult males in new groups (Marty et al., 2015). Moreover, male offspring remaining in their natal OMU for extended time periods may also facilitate their familiarity with the females in other OMUs, which may increase the likelihood of these males achieving successful OMU takeovers in the future. For instance, in a multilevel society of hamadryas baboons (Papio hamadryas), juvenile males leave their natal OMU at around two years of age. These males remain on the periphery of their natal breeding clan, which is composed of several patrilineally related OMUs (Sigg et al., 1982; Bergman et 
al., 2008; Ryan \& Hauber, 2016). Young males that have left their natal OMU employ a "follow-and-wait-strategy" (Mori et al., 2007), occasionally approaching infant and juvenile females to become familiar with these potential future sexual partners (Chalmers, 1986; see also for olive baboons: Danish \& Palombit, 2014). Thus, young hamadryas males benefit by remaining close to the breeding clan, with the goal of herding or kidnapping young females away from other units, to help establish their own OMU in the absence of potentially costly agonistic encounters with adult males (Kummer, 1968; Swedell \& Plummer, 2012).

Influenced by the differential strategies of both the leader males and young males, the pattern of age at natal dispersal varies even within the same species (e.g., Greenwood, 1980; Ekman \& Griesser, 2002; Marty et al., 2015). In primates that form an age-graded male hierarchy such as gorillas, young adult males may be tolerated and delay dispersal from a breeding social unit because they are socially subordinate and smaller than the adult male (Melissa, 1995). These 'black-back' males are usually the offspring of the dominant, 'silver-back' leader male, and may eventually inherit their father's dominant position by remaining in the group (Bradley et al., 2004; Douadi et al., 2010). In addition, 'silver-back' males appear to concede some matings to black-backs so that they will stay, because 'silver-back' males may avoid takeover by having their sons to defend against other units in the between-unit competition.

The same-sex tolerance of the alpha/leader male to young males can often be explained by kin selection (Hamilton, 1964; Maynard-Smith, 1964). Individuals are predicted to be more tolerant of kin than non-kin (Kappeler, 2008), which may affect the dispersal strategies of young male primates from their natal OMU. For instance, short-beaked common dolphins (Delphinus delphis) disperse to a single geographic location with related individuals (Ball et al., 2017). In cooperatively breeding brown jays (Cyanocorax morio), males that have dispersed from their natal territory are accepted into new groups that already contain at least one relative (Williams \& Rabenold, 2010). In polyembryonic wasps, soldier larvae are less likely to attack kin than non-kin (Giron \& Strand, 2004). In primates, leader males may benefit via inclusive fitness by tolerating their own sub-adult male offspring delaying dispersal from their breeding group (Perlman et al., 2016). Young males remaining in the breeding group may obtain more reproductive opportunities later in their lives than by dispersing early, which will also benefit 
their father via inclusive fitness. Such dispersal patterns may thus reflect the balance between the benefits and costs of intra-sexual competition and any inclusive fitness to both leader and younger males (Kappeler \& van Schaik, 2002). However, how different social and environmental factors affect variation in male dispersal strategies in primates still remains unclear (Shultz et al., 2011).

The golden snub-nosed monkey (Rhinopithecus roxellana) is an endangered Asian colobine endemic to the temperate forests of the mountainous highlands of southern and central China (Qi et al., 2008). The basic social unit of this species is the one-male unit (OMU), each of which is comprised of a single adult leader male, several adult females, and their infant and immature offspring. Unique to most Asian colobines, golden snub-nosed monkeys live in a multi-level society (MLS). The main social group of the $R$. roxellana MLS is the breeding band, which is formed from several OMUs that move, forage and rest together (Kirkpatrick \& Grueter, 2010; Grueter et al., 2012; Qi et al., 2014). The breeding band is followed by an all-male band (AMB) at a distance of 0.2 to $2.7 \mathrm{~km}$, comprised of ousted leader males and multiple juvenile/sub-adult males (Grueter et al., 2017; Qi et al., 2017). Given this spatial separation, the opportunities to get familiar with females are highly restricted in an AMB, compared to a breeding band, since the leader males in breeding bands coordinate attack on the AMB to drive them away from the females (Qi et al., 2017). Leader males evict young males prior to reaching sexual maturity from their natal OMUs (Qi et al., 2009; Yao et al., 2011). Females breed in their natal OMUs or transfer to a different OMU before adolescence if their father still remains the leader male of their natal OMU (Qi et al., 2009).

Using data from a 17-year study of the behaviour and ecology of a freeranging group of golden snub-nosed monkeys in the Zhouzhi National Nature Reserve located in Qinling Mountains, we found two male dispersal strategies. The most common is for males to disperse from their natal group as juveniles. The second strategy, recorded in six cases, is to delay dispersal until sub-adulthood. Here, we investigate if age of natal male dispersal is affected by leader male tenure. Leader males with long tenures have a high likelihood of being the sire of the older natal males born in the OMU and these leader males may gain inclusive fitness benefits from letting their sons stay in the group. Therefore, we hypothesize that young males have the possibility to remain longer in their natal group if the leader male has a long tenure. 


\section{Material and methods}

\subsection{Study site and subjects}

The study was carried out in the Zhouzhi National Nature Reserve (ZNNR), which is located on the northern slope of the Qinling Mountains $\left(108^{\circ} 14^{\prime}-\right.$ $108^{\circ} 18^{\prime} \mathrm{E}, 33^{\circ} 45^{\prime}-33^{\circ} 50^{\prime} \mathrm{N}$, with an altitude range from 1400 to $2890 \mathrm{~m}$ ), Shaanxi Province, P.R. China (Qi et al., 2008). Two troops of golden snubnosed monkeys are present in the area: (i) the east range troop (ERT) and (ii) the west range troop (WRT). The WRT was the subject of this work. The study animals were provisioned with corn seed to enable close observation. The provisioned food does not fulfill the daily individual energetic demands of the animals, and is only provided prior to observation times (approximately 5-6 h per day with observation occurring for approximately 6 months per year). For the remaining time, the monkeys forage, move and rest freely in the wild (Zhang et al., 2006; Tan et al., 2007; Qi et al., 2009). We therefore conclude that provisioning is unlikely to affect the dispersal behaviour of the monkeys. The WRT consisted of eight OMUs and an AMB in December 2001, and 16 OMUs and an AMB in June of 2016.

\subsection{Data collection}

Data were collected from December 2001 until June 2016. Observations were only made during the winter and spring of each year. Age groups were identified using the methods described by Qi et al. (2009): adult male ( $>7$ years old), adult female ( $>6)$, sub-adult male (4-7), sub-adult female (4-5), juvenile (1-3) and infant $(<1)$. Individuals could be recognized using one or more key physical characters, such as pelage coloration, hair crown pattern, and scars left by injuries (Qi et al., 2008).

We chose one OMU as the focal unit per day to record the behavioural data. We scanned behaviours of all the individuals of focal OMUs twice daily from a distance of between 0.5 and $50 \mathrm{~m}$ after food provisioning at 10:00 am and 14:00 pm. Spatial proximity between individuals was defined using the nearest distance method (Wey et al., 2008). We recorded the nearest individuals of the focal individual by focal animal sampling and instantaneous scan sampling at two-minute intervals to evaluate the association strength between individuals.

Immature males that delayed dispersal originated from three OMUs: BZTOMU, BX-OMU, and JB-OMU. We therefore investigated these units more 
thoroughly by using behavioural data to analyse affiliations among individuals within each of these units. The JB-OMU, was a marginal unit of the breeding band, and during the time of our observation of this unit (May 2003 to February 2014) was not stable. For this OMU, we only recorded its basic social composition and dynamics. For the other two OMUs, proximity data of the 24 individuals in the BZT-OMU were collected by focal animal sampling and instantaneous scan sampling at two-minute intervals. The total observation time was $925 \mathrm{~h}$ over a 12-month period (November 2004 to May 2005 and March 2011 to December 2011). The same measurements were also recorded for the BX-OMU between September 2015 until June 2016; a total $480 \mathrm{~h}$ were recorded over six months.

\subsection{Statistical analysis}

We calculated the mean tenure period in years for each OMU leader male, to estimate the stability of each OMU. Spatial proximity was used to assess the social association via preference/avoidance between two or more individuals within each OMU (Whitehead, 2008). We used these spatial proximity data to calculate an association index (AI) based on the Half-Weighted Index (HWI) using SOCPROG V2.1., and also measured the strength of social associations between individuals, principal coordinates, and the sociogram of the association network (Whitehead, 2009). Kaplan-Meier survival analysis was conducted with SPSS V19.0 package (SPSS Inc., Chicago). Tests were two-tailed, with the significance level set at $P<0.05$. Average values are expressed as mean $\pm \mathrm{SD}$.

\subsection{Partition matrix permutation test}

For each OMU, a matrix of association index was generated, whose $i j$ th elements represented the association index between the $i$ th and $j$ th individuals. These dyadic data are not independent because some dyads share the same individuals, e.g., when interactions between two individuals were recorded on different days. These association index data thus violate one of the main criteria that underlie the Mann-Whitney $U$-test, which assumes that all observations are independent. Therefore this test cannot be used for matrix data.

Whitehead et al. (2009) report a matrix permutation test to compare the means of the AI between two categories of dyads (category $\alpha$, associations between natal males and a leader male; and category $\beta$, associations between natal males and females in the same unit). This method randomly permutes 
a matrix, and calculates the probability of the difference in means of the AI between two categories of dyads being greater than the original value using a Monte-Carlo algorithm (Whitehead, 2009).

Base on this method, we developed a novel nonparametric test, the Partition Matrix Permutation Test (PMPT), to perform a comparison of association indices for multiple units. The procedure of permutation comprises of six steps. (i) The association index is standardized, such that the unbalanced number of different categories in different units will have a same expected mean value. This is done by subtracting the mean AI of all dyads and then dividing by the standard deviation. (ii) A random vector (denoted as $\mathbf{C}$ ) consisting of 1 to $n$ for each matrix (denoted as $\mathbf{B}_{i}$ ) is generated, where $n$ is the number of individuals within the unit and each number appears exactly once in this vector. (iii) A permutation matrix $\mathbf{B}_{i}^{\prime}$, whose $j k$ th element $B_{i j k}^{\prime}=B_{i C_{j} C_{k}}$ is generated, then the value of AI between the $i j$ th individuals is changed after permutation. (iv) The AIs of the two categories of dyads from the permuted matrices into two vectors, $\mathbf{D}_{1}$ and $\mathbf{D}_{2}$ are sampled. (v) The difference (denoted as $d$ ) between the means of the two vectors: $d=\overline{\mathbf{D}}_{1}-\overline{\mathbf{D}}_{2}$ is calculated. (vi) Finally, the permutation is repeated (e.g., for 99999 times) using a Monte-Carlo algorithm, and the probability that $d$ is greater than the original difference is calculated to obtain an unbiased estimate of significance.

\subsection{Ethical standards}

All research protocols reported here adhere to the regulatory requirements and were approved by the animal care committee of the Wildlife Protection Society of China (SL-2012-42). The genetic sampling received the clearance from, and complied with the protocols approved by, the specialist committee of the State Forestry Administration of China (SFA-LHXZ-2012-2788), and Chinese Academy of Science.

\section{Results}

\subsection{Natal dispersal age of male offspring}

From December 2001 to June 2016, 258 infants were born in the WRT breeding band, 17 (6.59\%) of which died of natural causes within their first six months of life. Of the surviving offspring, 89 were female and 152 were 
male. Forty of these male offspring were still infants or juveniles at the end of this study. During the study period, we recorded a total of 112 males dispersing from their natal OMU. Of these 112 males, the majority (106; 96.4\%) dispersed to the AMB as a juvenile before reaching sexual maturity. However, six male offspring unexpectedly remained in their natal OMU until adulthood or late subadulthood, dispersing at a mean age of $6.67 \pm$ 1.54 years $(N=6)$. The mean age of dispersal of the other 106 males was significantly younger $(3.34 \pm 0.70$ years; $U=3.00, p<0.001)$. The six males that delayed dispersal were each born into one of three OMUs: three males, BF, BY, and BXE were born into the BX-OMU, the male $\mathrm{XJ}$ was born into the JB-OMU, and the males ST and PD were both born into the BZT-OMU. Two of these six males established their own OMU, whereas the other four males transferred to the AMB. There thus appears to be two male dispersal patterns in this group of golden snub-nosed monkeys. The most common is for males to disperse from their natal OMU as juveniles. The second, less common pattern, is for males to remain in their natal OMU until they are sub-adults or young adults and then to disperse.

\subsection{Tenure of leader males}

During the study period, within the WRT breeding band a total of 48 different males achieved OMU leader male status. In seven cases, the leader male's tenure could not be estimated because he was already a leader male at the beginning of our study. In addition, 11 leader males had not completed their tenure by the end of the study.

For the 30 adult males with uncensored tenure length, the mean tenure is $2.87 \pm 3.29$ years (ranging from 0.01 to 10.75 years, $N=30$, Figure 1 , see details in Table A1 in the Appendix). The mean tenure of leader males whose offspring delayed dispersal was $8.63 \pm 3.30$ years (BZT: 10.33 years, JB: 10.75 years, BX: 4.83 years). Since some tenure lengths were censored, Kaplan-Meier survival analysis was employed to test whether the probability of a natal male staying in the group decreases more rapidly when the resident male has a short tenure (tenure length shorter than BX) compared to when the resident male has a long tenure (tenure length longer than BX) (Figure 2). Results suggest that units with a leader male with a long tenure are more likely to have male offspring that delay dispersal compared to those with short tenure leader males ( $\mathrm{df}=1, p=0.000)$. 


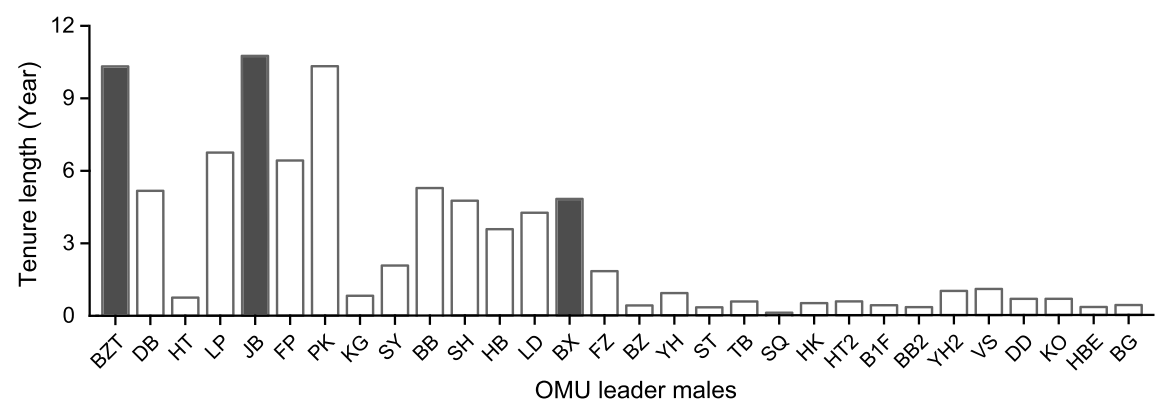

Figure 1. Histogram of leader male tenure length. Black bars indicate the tenure of the males whose presumed male offspring remained in their natal OMU into adulthood. White bars indicate the tenure of all other leader males. The infants in the PK unit were all female.

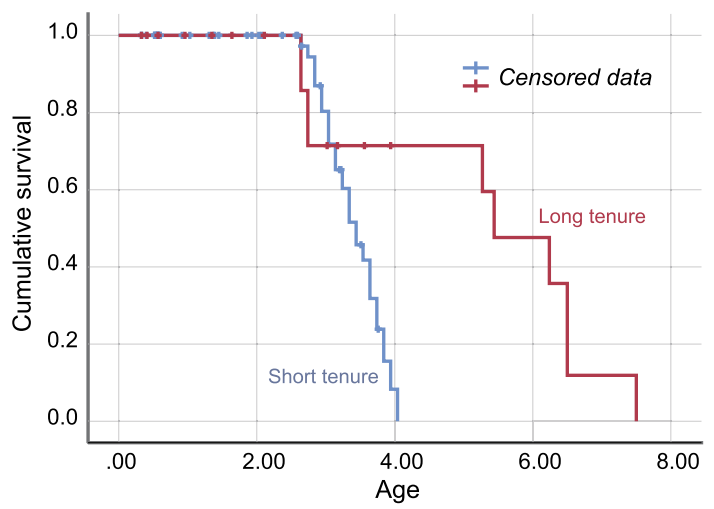

Figure 2. Kaplan-Meier survival analysis showing that the probability of a young male staying in its natal OMU decreases more steeply when the OMU leader male has a short tenure (tenure length shorter than BX, blue line) compared to leader males with a long tenure (tenure length longer than $\mathrm{BX}$, red line).

\subsection{Dynamics and dispersal history}

Over a 10-year period, 24 individuals were members of the BZT-OMU. These consisted of 14 offspring (four females and 10 males). Six of the male offspring dispersed into the AMB prior to BZT being replaced as the leader male. The remaining four male offspring disappeared from the OMU for unknown reasons (Figure 3a). Two of the six dispersing males, ST and PD, exhibited a different pattern. Both were born in the spring of 2002. Each dispersed from their natal OMU when approximately 3.5-years of age to the $\mathrm{AMB}$, in which they both remained for eight months, before returning to the BZT-OMU. During this time, the same leader male, BZT, continued 


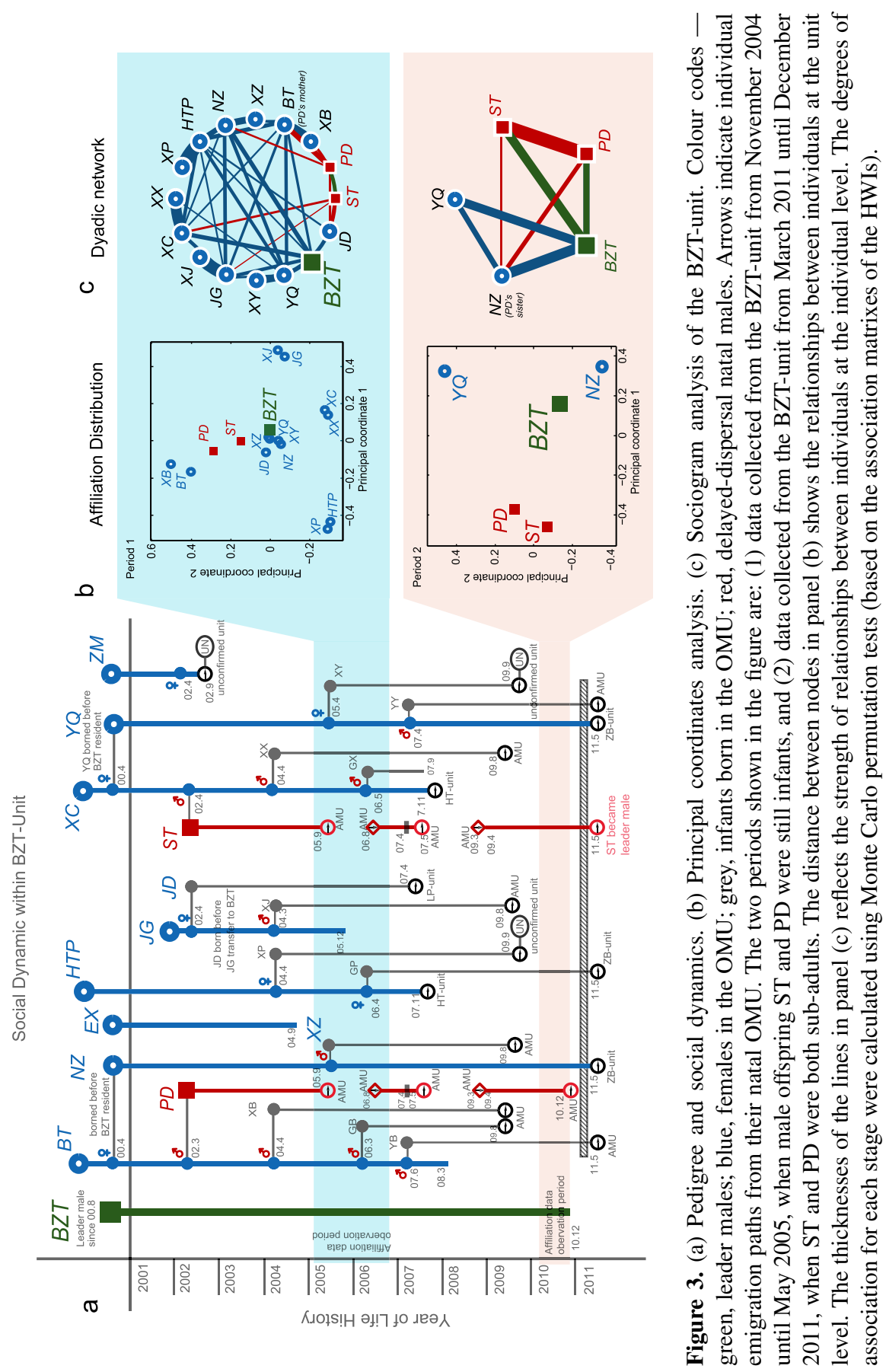


his tenure of the BZT-OMU. One year later both of these juvenile males transferred again to the AMB and remained there for 20 months. Both males returned to the BZT-OMU during April 2009 as sub-adults/young adults (seven years old). BZT remained the leader male. ST and PD remained in the OMU for a further 18 months. PD then transferred to the AMB, while ST attracted several females and became a leader male of a new OMU in the breeding band (Figure 3a).

The BX-OMU joined the WRT from a neighboring troop during September 2011. This unit was comprised of a leader male (BX), and eight adult females. Over the course of our five-year study these eight females produced 10 offspring (four females and six males). The male BY was born in 2010, with males BF and BXE both born in 2011. Each of these three males dispersed into the AMB during May 2016, when they had reached 5-6 years of age (sub-adult). The three other male offspring of this OMU were 3-4 years of age in 2016, when they were still present in their natal OMU (Figure 4a).

A total of 22 individuals were members of the JB-OMU over our fiveyear study period. These included 15 offspring (six females and nine males). After the leader male, JB, was usurped by another adult male, the 7.5 year old natal male XJ dispersed into the AMB with him.

\subsection{Variation in social affinity}

We used social network analysis (SNA) to calculate the association matrices that enabled us to compare social relationships among natal males and their OMU's leader male, and among natal males with the breeding females in both the $B Z T$ and $B X$-OMUs (Figures 3 and 4). These two Association Indices (AI) from both OMUs differed significantly (natal males and the leader male: $N=19$, mean $=0.6667$; natal males and the breeding females: $N=9$, mean $=0.3720$; PMPT test: $p=0.0067$ ). This suggests that young males that delay dispersal tend to socialize within their natal OMU more with the other males than with the breeding females.

The sociogram of the association network shows patterns of affiliation between individuals in these two units. We found that natal males exhibited strong relationships only with either the leader male or with other natal males of a similar age. They maintained weak associations with their mothers and the other adult females, and the young juvenile males, in their natal OMU (Figures 3, 4). This shows that natal males maintained affiliative social relationships principally with the leader adult male and other natal males. 

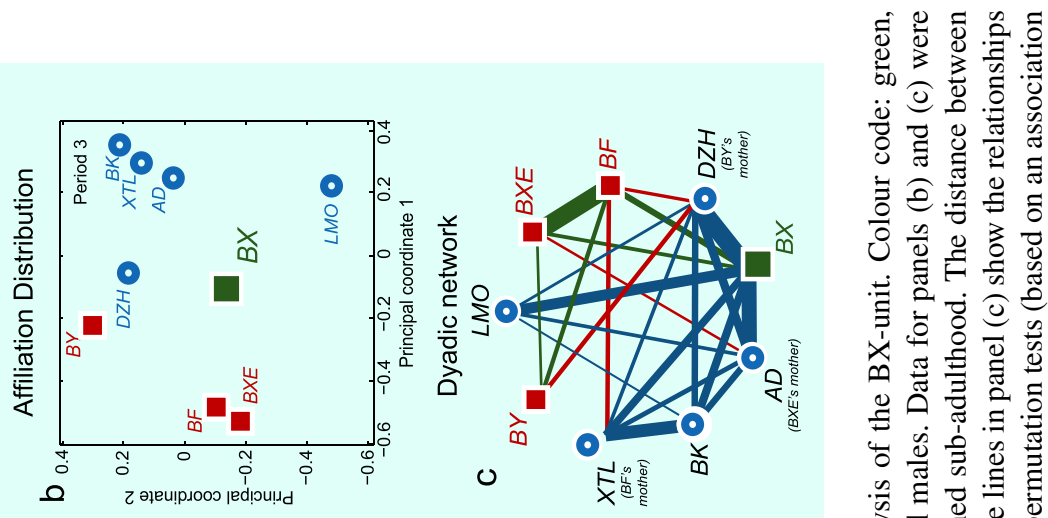
齐焉导 胥壱 छ

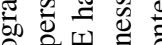
융

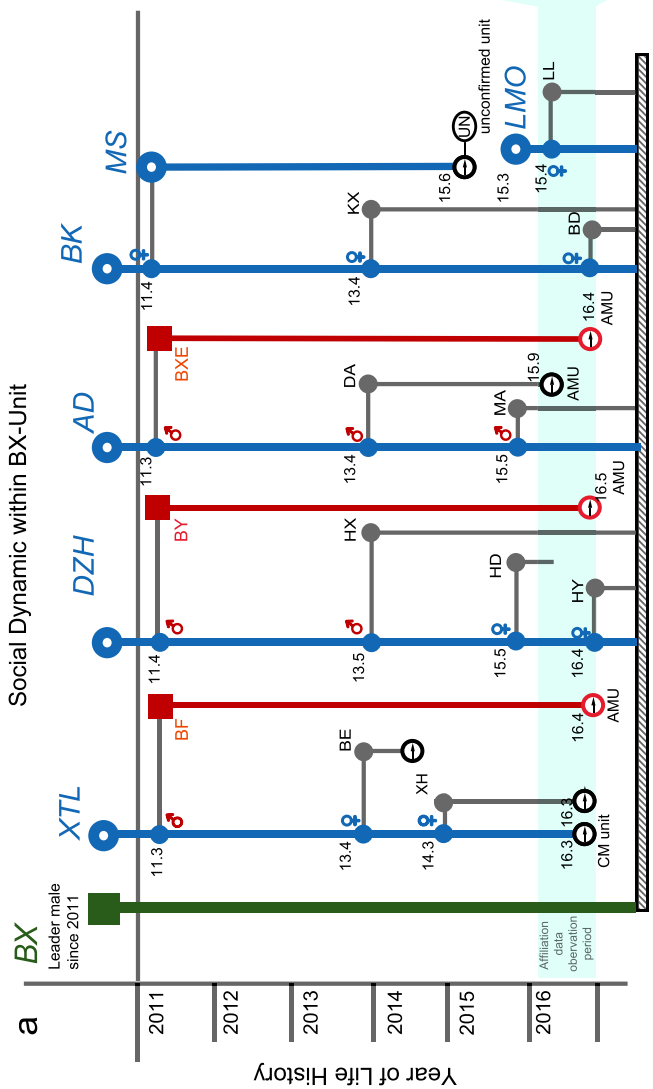

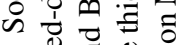
(2)

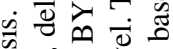

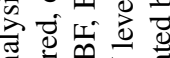

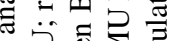

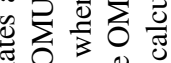

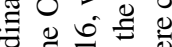
형 ठ :

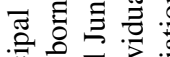

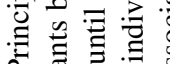

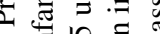

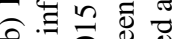
>ำ

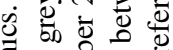
年

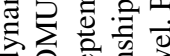

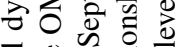

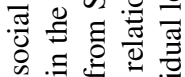

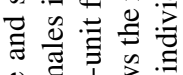

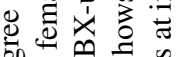

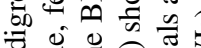

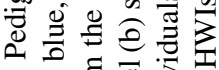

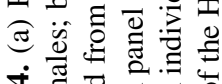
$+\because \widetilde{g}$

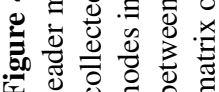


Additionally, there is no evidence of natal males mating with the females of their OMU in this species.

\section{Discussion}

We present new data that show that the average age of male offspring natal dispersal in golden snub-nosed monkeys is approximately 3.5 years. The average tenure of leader males is approximately 2.87 years. A lengthy tenure of leader males significantly delayed natal dispersal of male offspring. Social network analysis (SNA) showed that male offspring that delayed dispersal had stronger affiliative relationships with leader males and other males than with the females within their OMU.

The presence of young males may be a potential threat to leader males via increased competition for food and mates. The timing of the dispersal of young males from their OMU is thus likely to be at least partially dependent on the leader male's tolerance of these males. This tolerance may require males who delay dispersal to mainly associate with their leader males and similar-aged males, instead of interacting with adult females. Violation of such 'rules' may result in the leader males expelling the younger males from their natal OMU. Furthermore, we observed that younger males that delayed dispersal showed submissive behaviours to the leader males. These behaviours included approaching, and grooming of, the leader males, or young males lowering their bodies and presenting their hindquarters to the leader male in a similar manner as sexual solicitation (personal observation). Under such cases, the leader males would mount these young males to demonstrate dominance. All such behaviours seemed to increase leader male tolerance for young males to prolong their residence in the groups.

Such tolerant and strong male relationships often occur in populations in which the dominant male relies on cooperative support from subordinate males to defend their group or their home range against intruders. However, this is not the pattern we see in our study species. During our long term observations, we never observed that the young delayed dispersed males would help their leader males during aggressive inter-unit interactions over resources. Moreover, the young males would not help their leader males during takeover attempts by outside males. We therefore do not think that the delayed dispersal males benefitted their natal units in aggressive interactions. Kin selection often explains partially how tolerance between individuals 
may be maintained in some animal societies (Hamilton, 1964). For example, in Tibetan ground tits (Pseudopodoces humilis), males are more likely to help their close kin in parental care roles to rear offspring (Wang \& $\mathrm{Lu}$, 2018). Kinship between potential immigrants and residents increased the immigration success/recruitment in superb starlings (Lamprotornis superbus) (Pollack \& Rubenstein, 2015). In male primates, opportunities to become familiar with females are significantly reduced if males disperse from their natal unit into a bachelor group (Clutton-Brock, 2007). By extending their stay in their natal group, young males would increase their opportunities to affiliate and initiate social bonding with young females in other units, and thus increase the likelihood of establishing their own breeding unit via female recruitment in the future. In golden snub-nosed monkeys, female choice plays an important role during the processes leading up to the usurpation of an OMU leader male by another male in both the wild and in captivity (Ren et al., 2007; Fang et al., 2018). In this study the male ST, who delayed dispersal, successfully became an OMU leader without first transferring to the AMB soon after his natal BZT-unit collapsed. If these delayed dispersers are more successful in becoming OMU leaders, then a leader male could gain increased inclusive fitness by letting his offspring remain in the group. In contrast, leader males that are unrelated to the natal males would not gain such inclusive fitness benefits and this may be the reason why we never observed delayed dispersal from groups with new leader males. Thus, the cases of delayed dispersal appear to be consistent with kin selection theory. Furthermore, such tactics are only exhibited when leader males have a lengthy tenure of their OMU, which enables their sons to have enough time to reach maturity in their natal OMU, and have the ability to affiliate with females in other units. Otherwise, a young male would be evicted by the new leader male directly after the usurpation of his father. This may explain why only the units with lengthy tenure males have delayed dispersal males.

The young males that delayed their dispersal from their natal OMUs were able to maintain a long-term bond with their OMU leader males and their male siblings, which may be of benefit if they transfer to an AMB. Young males that lived in their natal OMU for extended time periods might enhance their social affiliation with their father and other males within their OMU. We found that the delayed-dispersal male XJ transferred into the AMB with his father JB after JB had been usurped by another male. Within the AMB, both $\mathrm{XJ}$ and JB exhibited strong social affiliation to each other and effectively 
competed cooperatively together to achieve a high rank in the AMB (Qi et al., 2017).

Although extra-pair copulations among individuals have been recorded in snub-nosed monkeys, there is no evidence of father-son recognition in our study species (Qi et al., submitted). Therefore, leader males and their offspring may not be able to recognize each other as kin. It is possible that leader males can even tolerate the unrelated young males because they perceive all natal males as their offspring. Moreover, extra-group paternity often occurs before an OMU takeover (unpublished work), which means that it is likely that natal males that delay dispersal are the true offspring of a leader male with a lengthy OMU tenure.

This is the first report of delayed male dispersal in Asian colobines (Kirkpatrick, 2011). A seemingly lack of this behaviour in other Asian colobines may be related to the social structure of snub-nosed monkeys (Rhinopithecus spp.). Although the basic social organization is the OMU, in most Asian colobine species other than $R$. roxellana, each OMUs is isolated from other OMUs, and occupies an independent home range (Grueter \& Zinner, 2012). Direct contact between individuals from different OMUs is therefore more restricted than in the MLS of $R$. roxellana, which means even if the leader male tolerates his sons staying in the unit, the young males can only have relationships with females in their own unit. Unique to other Asian colobines, golden snub-nosed monkeys have a nested and highly-cohesive social structure. Several OMUs share overlapping home ranges, and aggregate to form a large breeding band (Qi et al., 2014). This multilevel social organization allows the possibility of affiliation among units, which may give young males opportunities to become familiar with females in other units. The evolutionary pathway of golden snub-nosed monkeys from independent OMUs to a cohesive breeding band, thus enables males to use alternative reproductive tactics.

In conclusion, this study reports new results showing that the mean tenure length of leader males in a primate MLS are associated with delayed dispersal in their male offspring. Our long-term observations revealed that young males that delay dispersal build stronger associations with their leader male and other male offspring within their OMU, which may confer future benefits via enhanced access to females. Tolerating delayed dispersal in male offspring may also offer benefits to leader males via inclusive fitness. This 
study provides new information on how kin selection may affect the male reproductive strategies of golden snub-nosed monkeys, and may also increase the understanding of the causes and consequences of different dispersal and migratory strategies in non-human primates in general.

\section{Acknowledgements}

Gu Fang and Xiao-Min Gao contributed equally to this article. We thank Zhouzhi National Nature Reserve for giving us permission to carry out the research. This study was supported by the National Natural Science Foundation of China (31622053, 31730104), the Promotional project for Innovation team, the Department of Science and Technology of Shaanxi Prov. China (2018TD-017), the National Key Program of Research and Development, Ministry of Science and Technology of China (2016YFC0503200), Strategic Priority Research Program of the Chinese Academy of Sciences (XDB31020302), and Northwest University Graduate Innovation and Creativity Funds (YZZ17156). DWD is supported by a Talents 100 Fellowship of Shaanxi Province. We thank Dr. Kang Huang for assistance with data analysis, and all of the members of the golden snub-nosed monkey Research Team at the College of Life Science, Northwest University. We are also grateful to the anonymous reviewers for your patience and comments on the previous version of this draft.

\section{References}

Alberts, S.C. \& Altmann, J. (1995). Balancing costs and opportunities: dispersal in male baboons. - Am. Nat. 145: 279-306.

Andersson, M. (1994). Sexual selection. — Princeton University Press, Princeton, NJ.

Arcese, P. (1989). Intrasexual competition, mating system and natal dispersal in song sparrows. - Anim. Behav. 38: 958-979.

Ball, L., Shreves, K., Pilot, M. \& Moura, A.E. (2017). Temporal and geographic patterns of kinship structure in common dolphins (Delphinus delphis) suggest site fidelity and female-biased long-distance dispersal. — Behav. Ecol. Sociobiol. 71: 123.

Bergman, T.J., Phillipsconroy, J.E. \& Jolly, C.J. (2008). Behavioral variation and reproductive success of male baboons (Papio anubis $\times$ Papio hamadryas) in a hybrid social group. Am. J. Primatol. 70: 136-147.

Bradley, B.J., Doran-Sheehy, D.M., Lukas, D., Boesch, C. \& Vigilant, L. (2004). Dispersed male networks in western gorillas. - Curr. Biol. 14: 510-513.

Chalmers, N.R. (1986). On socialization in hamadryas baboons. - Bucknell University Press, Lewisburg, PA. 
Clutton-Brock, T.H. (2007). Sexual selection in males and females. — Science 318: 18821885.

Danish, L.M. \& Palombit, R.A. (2014). "Following," an alternative mating strategy used by male olive baboons (Papio hamadryas anubis): quantitative behavioral and functional description. - Int. J. Primatol. 35: 394-410.

DeVore, I. (1965). Primate behavior; field studies of monkeys and apes. - Holt, Rhinehart and Winston, New York, NY.

Douadi, M.I., Gatti, S., Levrero, F., Duhamel, G., Bermejo, M., Vallet, D., Menard, N. \& Petit, E.J. (2010). Sex-biased dispersal in western lowland gorillas (Gorilla gorilla gorilla). Mol. Ecol. 16: 2247-2259.

Drickamer, L.C. \& Vessey, S.H. (1973). Group changing in free-ranging male rhesus monkeys. - Primates 14: 359-368.

Ekman, J. \& Griesser, M. (2002). Why offspring delay dispersal: experimental evidence for a role of parental tolerance. — Proc. Roy. Soc. Lond. B: Biol. Sci. 269: 1709-1713.

Fang, G., Chen, J., Pan, R.L., Qi, X.G. \& Li, B.G. (2018). Female choice impacts residential male takeover in golden snub-nosed monkeys (Rhinopithecus roxellana). — Zool. Res. 39: 266-271.

Giron, D. \& Strand, M.R. (2004). Host resistance and the evolution of kin recognition in polyembryonic wasps. — Proc. Roy. Soc. Lond. B: Biol. Sci. 271: S395-S398.

Greenwood, P.J. (1980). Mating systems, philopatry and dispersal in birds and mammals. Anim. Behav. 28: 1140-1162.

Grueter, C.C., Chapais, B. \& Zinner, D. (2012). Evolution of multilevel social systems in nonhuman primates and humans. - Int. J. Primatol. 33: 1002-1037.

Grueter, C.C., Qi, X., Li, B. \& Li, M. (2017). Multilevel societies. — Curr. Biol. 27: R984R986.

Grueter, C.C. \& Zinner, D. (2012). Evolution of multilevel social systems in nonhuman primates and humans. - Int. J. Primatol. 33: 1002-1037.

Hamilton, W.D. (1964). The genetical evolution of social behaviour I, II. - J. Theor. Biol. 7: 1-52.

Höner, O.P., Wachter, B., East, M.L., Streich, W.J., Wilhelm, K., Burke, T. \& Hofer, H. (2007). Female mate-choice drives the evolution of male-biased dispersal in a social mammal. — Nature 448: 798-801.

Huffman, M. (1991). History of the Arashiyama Japanese macaque in Kyoto, Japan. - In: The monkeys of Arashiyama (Fedigan, L. \& Asquith, P., eds). State University of New York Press, New York, NY, p. 21-53.

Kappeler, P.M. (2008). Genetic and ecological determinants of primate social systems. - In: Ecology of social evolution (Korb, J. \& Heinze, J., eds). Springer, Heidelberg, p. 225-243.

Kappeler, P.M. \& van Schaik, C.P. (2002). Evolution of primate social systems. - Int. J. Primatol. 23: 707-740.

Kirkpatrick, R.C. (2011). The Asian colobines: diversity among leafeating monkeys. - In: Primates in perspective (Campbell, C.J., Fuentes, A., MacKinnon, K.C., Bearder, S.K. \& Stumpf, R.M., eds). Oxford University Press, New York, NY, p. 189-202. 
Kirkpatrick, R.C. \& Grueter, C.C. (2010). Snub-nosed monkeys: multilevel societies across varied environments. — Evol. Anthropol. Iss. News Rev. 19: 98-113.

Kummer, H. (1968). Social organization of hamadryas baboons. - University of Chicago Press, Chicago, IL.

Marty, P.R., Hodges, K., Agil, M. \& Engelhardt, A. (2015). Alpha male replacements and delayed dispersal in crested macaques (Macaca nigra). — Am. J. Primatol. 79: 53-55.

Maynard-Smith, J. (1964). Group selection and kin selection. — Nature 201: 1145-1147.

Melissa, R. (1995). Effects of body size and social context on the arboreal activities of lowland gorillas in the Central African Republic. - Am. J. Phys. Anthropol. 97: 413433.

Mitani, J.C., Gros-Louis, J. \& Richards, A.F. (1996). Sexual dimorphism, the operational sex ratio, and the intensity of male competition in polygynous primates. - Am. Nat. 147: 966-980.

Mori, A., Yamane, A., Sugiura, H., Shotake, T., Boug, A. \& Iwamoto, T. (2007). A study on the social structure and dispersal patterns of hamadryas baboons living in a commensal group at Taif, Saudi Arabia. — Primates 48: 179-189.

Packer, C.R. (1977). Inter-troop transfer and inbreeding avoidance in Papio anubis in Tanzania. - Anim. Behav. 27: 1-36.

Perlman, R.F., Borries, C. \& Koenig, A. (2016). Dominance relationships in male Nepal gray langurs (Semnopithecus schistaceus). — Am. J. Phys. Anthropol. 160: 208-219.

Pollack, L. \& Rubenstein, D.R. (2015). The fitness consequences of kin-biased dispersal in a cooperatively breeding bird. — Biol. Lett. 11: 20150336.

Pusey, A.E. \& Packer, C. (2012). Philopatry and dispersal. — In: The evolution of primate societies (Mitani, J.C., Call, J., Kappeler, P.M., Palombit, R.A. \& Silk, J.B., eds). University of Chicago Press, Chicago, IL.

Qi, X.G., Garber, P.A., Ji, W.H., Huang, Z.P., Huang, K., Zhang, P., Guo, S.T., Wang, X.W., He, G., Zhang, P. \& Li, B.G. (2014). Satellite telemetry and social modeling offer new insights into the origin of primate multilevel societies. - Nature Comm. 5: 5296.

Qi, X.G., Huang, K., Fang, G., Grueter, C.C., Dunn, D.W., Li, Y.L., Ji, W.H., Wang, X.Y., Wang, R.T., Garber, P.A. \& Li, B.G. (2017). Male cooperation for breeding opportunities contributes to the evolution of multilevel societies. — Proc. Roy. Soc. Lond. B: Biol. Sci. 284: 20171480.

Qi, X.G., Li, B.G., Garber, P.A., Ji, W.H. \& Watanabe, K. (2009). Social dynamics of the golden snub-nosed monkey (Rhinopithecus roxellana): female transfer and one-male unit succession. - Am. J. Primatol. 71: 670-679.

Qi, X.G., Li, B.G. \& Ji, W.H. (2008). Reproductive parameters of wild female Rhinopithecus roxellana. - Am. J. Primatol. 70: 311-319.

Ren, B.P., Liang, B., Zhang, S.Y., Li, Q.F. \& Grueter, C.C. (2007). Effects of temporary removal and replacement of the alpha male on social behavior of the captive Sichuan snub-nosed monkey (Rhinopithecus roxellana). — Acta Zool. Sinica 53: 755-762.

Ryan, A.M. \& Hauber, M.E. (2016). Group compositional changes impact the social and feeding behaviors of captive hamadryas baboons (Papio hamadryas). - Zoo Biol. 35: $137-146$. 
Shultz, S., Opie, C. \& Atkinson, Q.D. (2011). Stepwise evolution of stable sociality in primates. - Nature 479: 219-222.

Sigg, H., Stolba, A., Abegglen, J.J. \& Dasser, V. (1982). Life history of hamadryas baboons: physical development, infant mortality, reproductive parameters and family relationships. — Primates 23: 473-487.

Silk, J.B., Beehner, J., Bergman, T., Crockford, C., Engh, A., Moscovice, L., Wittig, R., Seyfarth, R.M. \& Cheney, D. (2009). The benefits of social capital: close social bonds among female baboons enhance offspring survival. — Proc. Roy. Soc. Lond. B: Biol. Sci. 276: 99-104.

Steely, C.J., Walker, J.A., Jordan, V.E., Beckstrom, T.O., McDaniel, C.L., St. Romain, C.P., Bennett, E.C., Robichaux, A., Clement, B.N., Raveendran, M., Worley, K.C., PhillipsConroy, J., Jolly, C.J., Rogers, J., Konkel, M.K. \& Batzer, M.A. (2017). Alu insertion polymorphisms as evidence for population structure in baboons. - Gen. Biol. Evol. 9: 2418-2427.

Swedell, L. \& Plummer, T. (2012). A papionin multilevel society as a model for hominin social evolution. — Int. J. Primatol. 33: 1165-1193.

Tan, C.L., Guo, S.T. \& Li, B.G. (2007). Population structure and ranging patterns of Rhinopithecus roxellana in Zhouzhi National Nature Reserve, Shaanxi, China. — Int. J. Primatol. 28: 577-591.

Teichroeb, J., Wikberg, E. \& Sicotte, P. (2011). Dispersal in male ursine colobus monkeys (Colobus vellerosus): influence of age, rank and contact with other groups on dispersal decisions. - Behaviour 148: 765-793.

Teichroeb, J.A. \& Jack, K.M. (2017). Alpha male replacements in nonhuman primates: variability in processes, outcomes, and terminology. — Am. J. Primatol. 79: e22674. DOI:10. 1002/ajp.22674.

Van Noordwijk, M.A. \& Van Schaik, C.P. (2004). Sexual selection and the careers of primate males: paternity concentration, dominance-acquisition tactics and transfer decisions. In: Sexual selection in primates: new and comparative perspectives (Kappeler, P.M., ed.). Cambridge University Press, Cambridge, p. 208-229.

Wang, C.C. \& Lu, X. (2018). Hamilton's inclusive fitness maintains heritable altruism polymorphism through $\mathrm{rb}=$ c. - Proc. Natl. Acad. Sci. USA 115: 1860.

Wang, W.R. \& Yao, M. (2017). Fine-scale genetic structure analyses reveal dispersal patterns in a critically endangered primate, Trachypithecus leucocephalus. - Am. J. Primatol. 79: e22635.

Wey, T., Blumstein, D.T., Shen, W. \& Jordán, F. (2008). Social network analysis of animal behaviour: a promising tool for the study of sociality. — Anim. Behav. 75: 333-344.

Whitehead, H. (2008). Analyzing animal societies. - University of Chicago Press, Chicago, IL.

Whitehead, H. (2009). Socprog programs: analysing animal social structures. - Behav. Ecol. Sociobiol. 63: 765-778.

Williams, A. \& Rabenold, K.N. (2010). Male-biased dispersal, female philopatry, and routes to fitness in a social corvid. - J. Anim. Ecol. 74: 150-159. 
Yao, H., Liu, X., Stanford, C., Yang, J., Huang, T., Wu, F. \& Li, Y. (2011). Male dispersal in a provisioned multilevel group of Rhinopithecus roxellana in Shennongjia Nature Reserve, China. - Am. J. Primatol. 73: 1280-1288.

Zhang, P., Watanabe, K., Li, B.G. \& Tan, C.L. (2006). Social organization of sichuan snubnosed monkeys (Rhinopithecus roxellana) in the Qinling Mountains, Central China. Primates 47: 374-382.

Zhu, P.F., Ren, B.P., Garber, P.A., Xia, F., Grueter, C.C. \& Li, M. (2016). Aiming low: a resident male's rank predicts takeover success by challenging males in Yunnan snubnosed monkeys. — Am. J. Primatol. 78: 974-982. 
Table A1.

Composition of all OMUs.

\begin{tabular}{|c|c|c|c|c|c|c|}
\hline $\begin{array}{l}\text { Name of } \\
\text { resident } \\
\text { male }\end{array}$ & $\begin{array}{c}\text { Have } \\
\text { philopatric } \\
\text { males or } \\
\text { not }\end{array}$ & $\begin{array}{l}\text { Start- } \\
\text { ing } \\
\text { time }\end{array}$ & $\begin{array}{c}\text { Terminal } \\
\text { time }\end{array}$ & $\begin{array}{l}\text { Tenure } \\
\text { (year) }\end{array}$ & $\begin{array}{l}\text { Number } \\
\text { of adult } \\
\text { females }\end{array}$ & $\begin{array}{c}\text { Number } \\
\text { of off- } \\
\text { spring }\end{array}$ \\
\hline $\mathrm{BZT}$ & Yes & 2000.08 & 2010.12 & 10.33 & $2-13$ & 14 \\
\hline DB & No & 2002.08 & 2008.10 & 5.17 & $4-6$ & 15 \\
\hline HT & No & 2002.08 & 2003.05 & 0.75 & 2 & 3 \\
\hline LP & No & 2003.03 & 2009.12 & 6.75 & $3-10$ & 17 \\
\hline JB & Yes & 2003.05 & 2014.02 & 10.75 & $2-6$ & 19 \\
\hline FP & No & 2003.07 & 2009.12 & 6.42 & $1-4$ & 9 \\
\hline PK & No & 2003.10 & 2014.02 & 10.33 & $3-7$ & 16 \\
\hline $\mathrm{SH}$ & No & 2009.12 & 2014.09 & 4.75 & $3-5$ & 10 \\
\hline KG & No & 2003.11 & 2004.09 & 0.83 & 3 & 3 \\
\hline SY & No & 2007.11 & 2009.12 & 2.08 & 3 & 6 \\
\hline $\mathrm{BB}$ & No & 2007.11 & 2013.02 & 5.25 & $4-9$ & 21 \\
\hline HB & No & 2011.03 & 2014.10 & 3.58 & 6 & 10 \\
\hline LD & No & 2011.09 & 2015.12 & 4.25 & $2-5$ & 10 \\
\hline $\mathrm{BX}$ & Yes & 2011.09 & 2016.06 & 4.83 & $4-5$ & 10 \\
\hline $\mathrm{FZ}$ & No & 2011.09 & 2013.06 & 1.83 & 3 & 8 \\
\hline BZ & No & 2012.04 & 2012.09 & 0.42 & 2 & 4 \\
\hline YH & No & 2012.02 & 2013.01 & 0.92 & 3 & 8 \\
\hline ST & No & 2012.08 & 2012.12 & 0.33 & 2 & 2 \\
\hline TB & No & 2012.09 & 2013.03 & 0.58 & 2 & 6 \\
\hline SQ & No & 2012.12 & 2012.12 & 0.014 & 2 & 0 \\
\hline $\mathrm{HK}$ & No & 2012.12 & 2013.06 & 0.50 & 2 & 4 \\
\hline HT2 & No & 2013.02 & 2013.09 & 0.58 & $5-9$ & 12 \\
\hline $\mathrm{B} 1 \mathrm{~F}$ & No & 2013.04 & 2013.09 & 0.42 & 4 & 7 \\
\hline BB2 & No & 2013.09 & 2013.12 & 0.33 & 2 & 2 \\
\hline YH2 & No & 2014.02 & 2015.02 & 1.00 & 0 & 2 \\
\hline VS & No & 2014.02 & 2015.03 & 1.08 & 2 & 9 \\
\hline $\mathrm{DD}$ & No & 2015.02 & 2015.09 & 0.67 & 2 & 3 \\
\hline $\mathrm{KO}$ & No & 2015.03 & 2015.10 & 0.67 & 5 & 8 \\
\hline BG & No & 2015.10 & 2016.03 & 0.33 & 4 & 3 \\
\hline HBE & No & 2015.09 & 2015.12 & 0.42 & 4 & 0 \\
\hline
\end{tabular}

